\title{
Perancangan Sistem Informasi Pendaftaran Santri Pesantren Moderen Daarul Muttaqien 1 Tangerang
}

\author{
Eka Wulansari Fridayanthie ${ }^{1}$, Aliffah Kusumaningrum ${ }^{2}$, Azis Sukma Dhiana ${ }^{3}$, Dzulfikar \\ Bahir $^{4}$ \\ 1234Universitas Bina Sarana Informatika \\ Email: ${ }^{1} \underline{e k a . e w f @ b s i . a c . i d, 2}{ }^{2}$ aliffah.akg@bsi.ac.id, ${ }^{3}$ azis.azs@bsi.ac.id, \\ ${ }^{4}$ dzulfikar.bahir@gmail.com
}

\begin{abstract}
Abstrak
Pada tahun ajaran baru adalah hal yang tidak dapat dihindari, karena hal tersebut merupakan salah satu tahapan yang harus dilalui untuk menjadi seorang santri di Pesantren Modern Daarul Muttaqien 1 Tangerang. Sistem penerimaan santri baru di Pesantren Modern Daarul Muttaqien 1 Tangerang jika di lihat seperti ini : Calon santri datang langsung ke sekolah menemui bagian pendaftaran dan menanyakan informasi, bagian pendaftaran memberikan informasi kepada calon santri yang ingin mendaftar diharuskan membeli formulir, setelah itu bagian pendaftaran menerima pembayaran lalu memberikan formulir dan membuat 2 rangkap kwitansi, satu untuk calon santri satu untuk di arsipkan oleh tata usaha satu. Setelah formulir di isi semuanya, calon santri mengembalikan formulir berikut persyaratan ke bagian pendaftaran. Bagian pendaftaran harus memproses penerimaan santri baru berdasarakan rekapan formulir untuk menyerahkan kepada wakil kepala sekolah dan kepala sekolah untuk di tanda tangani. Hal tersebut harus dilakukan dengan cepat dan tepat. Untuk membantu memecahkan masalah dan memfasilitasi dalam proses pendaftaran atau penerimaan santri baru, maka diperlukan sistem informasi yang mendukung proses tersebut.
\end{abstract}

Kata Kunci: Perancangan Sistem Informasi, Sistem Pendaftaran Santri Baru

\begin{abstract}
In the new school year, it is unavoidable, because it is one of the stages that must be passed to become a student at the Modern Islamic Boarding School Daarul Muttaqien 1 Tangerang. The new student admission system at the Daarul Muttaqien 1 Tangerang Modern Islamic Boarding School looks like this: Prospective students come directly to the school to meet the registration section and ask for information, the registration section provides information to prospective students who want to register are required to buy a form, after that the registration section receives payment then give the form and make 2 copies of receipts, one for prospective students and one to be archived by administration one. After all the forms are filled in, prospective students return the form along with the requirements to the registration section. The registration department must process the admission of new students based on a recap of the form to submit to the vice principal and principal for signature. This must be done quickly and precisely. To help solve problems and facilitate the process of registering or accepting new students, an information system that supports the process is needed.
\end{abstract}

Keywords: Information System Design, New Student Registration System

\author{
1. Pendahuluan \\ Tangerang merupakan sekolah \\ yang Sejalan dengan perkembangan \\ teknologi informasi, mempunyai 2 (Dua) \\ jurusan yaitu IPA \& IPS. Jumlah santri-
}

santriwati yang sekolah di Pesantren Modern Daarul Muttaqien 1 ini setiap tahunnya meningkat. Semakin lama perkembangan dunia ilmu komputer sudah begitu pesat, sehingga dalam berbagai 
proses kegiatan selalu kita jumpai keberadaannya. Selama ini komputer dapat dipakai untuk membantu orang dalam memecahkan masalah, terutama dalam pengolahan data. Upaya meningkatkan kualitas pendidikan dapat terwujud ditunjang dengan Peningkatan kemampuan guru.

Guru salah satu komponen disekolah, merupakan unsur penting dalam menjalankan program dikelas sebagai pendidik, pengajar, dan pengelola kelas. Usaha dibidang pendidikan mengalami perkembangan yang cukup pesat. Dalam setiap proses transaksinya Pesantren Modern Daarul Muttaqien 1 Tangerang masih menggunakan sistem informasi yang belum handal atau masih manual, seperti Pembelian formulir, pengembalian formulir, pembayaran spp dan pembuatan laporan penerimaan siswa baru

Pada tahun ajaran baru adalah hal yang tidak dapat dihindari, karena hal tersebut merupakan salah satu tahapan yang harus dilalui untuk menjadi seorang santri di Pesantren Modern Daarul Muttaqien 1 Tangerang. Sistem penerimaan santri baru di Pesantren Modern Daarul Muttaqien 1 Tangerang jika di lihat seperti ini : Calon santri datang langsung ke sekolah menemui Bagian pendaftaran dan menanyakan informasi, bagian pendaftaran memberikan informasi kepada calon santri yang ingin mendaftar diharuskan membeli formulir, setelah itu bagian pendaftaran menerima pembayaran lalu memberikan formulir dan membuat 2 rangkap kwitansi, satu untuk calon santri satu untuk di arsipkan oleh tata usaha satu. Setelah formulir di isi semuanya, calon santri mengembalikan formulir berikut persyaratan ke bagian pendaftaran.

Bagian pendaftaran menerima kemudian memeriksa formulir dan persyaratan, lalu bagian pendaftaran merekap ke dalam microsoft exsel dan mengarsipkan formulir pendaftaran, setelah itu calon santri mendatangi bagian tata usaha untuk melakukan pembayaran SPP. Bagian tata usaha menerima pembayaran lalu membuat kwitansi 2 rangkap untuk calon santri, dan bagian tata usaha mengarsipakan kwitansi 1 rangkap untuk di jadikan sebagai bukti pembayaran, lalu bagian tata usaha menyerahkan kwitansi kepada calon santri dan calon santri menerima kwitansi pembayaran SPP.

Setelah jadwal penerimaan santri baru di tutup. Bagian pendaftaran akan membuat laporan penerimaan santri baru berdasarakan rekapan formulir untuk menyerahkan kepada wakil kepala sekolah dan kepala sekolah untuk di tanda tangani. Hal tersebut harus dilakukan dengan cepat dan tepat. Untuk membantu memecahkan masalah dan memfasilitasi dalam proses pendaftaran atau penerimaan santri baru, maka diperlukan sistem informasi yang mendukung proses tersebut.

\section{Metode Penelitian}

A. Metode Pengembangan Perangkat Lunak

Metode yang digunakan pada pengembangan perangkat lunak ini menggunakan model waterfall yang terbagi menjadi beberapa tahapan, yaitu (A. S. \& Shalahuddin, 2015, hal. 28)

\section{Analisis Kebutuhan}

Dalam tahap analisa kebutuhan perangkat lunak, memaparkan tentang sistem pengolahan data yang sedang berjalan pada Pesntren Modern Daarul Muttaqien 1 Tangerang sesuai dengan kebutuhan pengguna mulai dari proses pengisian formulir, melengkapi isian formulir, pembayaran, membuat laporan.

\section{Desain}

Pada tahap ini, perancangan suatu sistem berjalan untuk Pesantren Modern Daarul Muttaqien 1 Tangerang yang berupa gambaran antar muka, berdasarkan data yang telah dikumpulkan.

\section{Pengkodean}

Pada tahap ini tidak dilakukan pengkodean program, karena penulis hanya membuat desain persiapan. Setelah itu desain yang telah dibuat harus direalisasikan ke dalam sistem Memproses data sebagai program yang mendukung pengumpulan data, agar hasilnya sesuai dengan desain yang telah dibuat. Sehingga harus dibuat kedalam logical record structure (LRS).

\section{Pengujian}

Pada tahap ini dilakukan pengujian terhadap rancangan program yang sudah dibuat agar dapat mengetahui apakah sudah sesuai dengan yang 
diharapkan dengan memberikan desain rancangan yang terstruktur.

\section{B. Teknik Pengumpulan Data}

Metode yang digunakan untuk keperluan tugas akhir ini adalah:

1. Metode Wawancara

Suatu bentuk metode dengan mengajukan beberapa pertanyaan terhadap orang yang mempunyai peran penting pada objek penelitian kami atau narasumber. Penulis melakukan wawancara secara langsung kepada narasumber dan orang yang bergerak dibidang yang kami teliti, oleh karena itu kami mewawancarai bagian Wakil Kepala Sekolah Pesantren Modern Daarul Muttaqien 1 Tangerang mengenai Pendaftaran Siswa baru.

2. Metode Observasi

Dimana Penulis melakukan penelitian dan pengamatan secara langsung mengenai pelaksanaan kegiatan Pendaftaran pada Pesantrenn Modern Daarul Muttaqien 1 Tangerang.

3. Studi Pustaka

Metode ini menghasilkan kumpulan data yang diperbarui dari buku-buku, literaturliteratur dan catatan-catatan kuliah yang berkaitan dengan masalah yang akan dibahas serta yang berkaitan dengan penelitian.

Dalam mengatasi pemecahan masalah, penulis mengajukan suatu cara untuk meminimalkan masalah dalam proses penerimaan santri baru agar lebih baik dari sebelumnya yaitu menggunakan sistem komputerisasi dengan pertimbangan- pertimbangan sebagai berikut :

a. Menggunakan sistem penerimaan santri baru yang sudah terkomputerisasi, dengan dibuatkan aplikasi penerimaan santri baru berbasis web.

b. Dibuatkan apikasi untuk mempermudah proses pembuatan laporan.

c. Dibuatkan aplikasi untuk menyimpan data dalam bentuk database untuk mempermudah pencarian data dan memperbaharui data.

\section{Hasil dan Pembahasan}

Penerimaan santri baru merupakan hal awal yang dilakukan suatu institusi pendikikan yaitu sekolah sebelum kegiatan mengajar dan belajar dimulai setiap tahun ajaran baru. Oleh karena itu sistem penerimaan santri baru yang efektif harus dimiliki setiap sekolah. Hal ini dilakukan untuk menjaring setiap santri baru agar sesuai dengan kriteria yang diberikan oleh pihak sekolah demi menghasilkan santri-santriwati yang berbobot yang nantinya akan meningkatkan reputasi sekolah di masa yang akan datang.

Namun saat ini, sistem yang digunakan dalam proses penerimaan santri baru pada Pesantren Modern Daarul Muttaqien 1 Tangerang masih menggunakan sistem manual. Oleh karena itu, pada kesempatan ini kami ingin memaparkan sistem yang berjalan pada proses penerimaan santri baru di Pesantren Modern Daarul Muttaqien 1 Tangerang sebagai bahan perbandingan untuk merancang sistem yang baru.

Pada prosedur sistem berjalan ini akan menggunakan Diagram Activity disini akan membahas mengenai alur dari suatu kegiatan yang dilakukan oleh calon santri dalam melakukan pendaftaran sekolah.

Berikut adalah Activity diagram apabila santri melakukan pendaftaran ke sekolah.

1. Prosedur Pembelian Formulir Santri

Baru

Calon santri datang langsung ke sekolah menemui bagian pendaftaran dan menanyakan informasi, bagian pendaftaran memberikan informasi calon santri yang ingin mendaftar diharuskan membeli formulir, bagian pendaftaran menerima pembayaran lalu memberikan formulir dan membuat 2 rangkap kwitansi, satu untuk calon santri satu untuk di arsipkan oleh bagian tata usaha.

2. Prosedur Pengembalian Formulir Santri Baru

Setelah formulir di isi semuanya, calon santri mengembalikan formulir berikut persyaratan ke bagian pendaftaran. Bagian registrasi pertama menerima 
formulir dan persyaratan, kemudian menerima pendaftaran dan persyaratan, dan kemudian bagian pendaftaran merangkumnya ke Microsoft exsel dan mengarsipkan formulir pendaftaran.

3. Prosedur Pembayaran Santri Baru

Calon santri mendatangi bagian tata usaha untuk melakukan pembayaran SPP. Bagian tata usaha menerima pembayaran lalu membuat kwitansi 2 rangkap untuk calon santri, dan bagian tata usaha mengarsipakan kwitansi 1 rangkap untuk di jadikan sebagai bukti pembayaran, lalu bagian tata usaha menyerahkan kwitansi kepada calon santri dan calon santri menerima kwitansi pembayaran SPP.

4. Prosedur Laporan Penerimaan Santri Baru

Setelah jadwal penerimaan santri baru di tutup. Bagian pendaftaran membuat laporan penerimaan santri baru berdasarakan rekapan formulir untuk menyerahkan kepada wakil kepala sekolah dan kepala sekolah untuk di tanda tangani

Sistem pendaftaran santri yang telah terkomputerisasi ini dibuat untuk membantu proses pendaftaran santri baru pada Pesantren Modern Daarul Muttaqien 1 Tangerang lebih mudah, cepat dan dapat diakses dimana saja dan kapan saja. Berikut rincian pembagian halaman berdasarkan level pengguna

A.Kebutuhan Calon Santri :

A1.Calon santri melakukan login

A2.Calon santri dapat melakukan pendaftaran

A3.Calon santri dapat mencetak pendaftaran

A4.Calon santri melakukan pembayaran

B.Kebutuhan Admin :

B1.Admin harus login terlebih dahulu dengan menggunakan username dan password

B2.Admin dapat mengelola data pendaftaran

B3.Admin juga dapat mengelola data pembayaran.

\section{C.Kebutuhan Sistem}

C1.Sistem memvalidasi username \& password calon santri.
C2.Sistem mengirim NIS sementara dan password melalui email calon santri

\section{Rancangan Diagram Use Case}

Diagram ini menggambarkan model lengkap tentang siapa yang berperan selama kegiatan pendaftaran berlangsung.

\section{Use Case Diagram Pendaftaran Santri} Baru

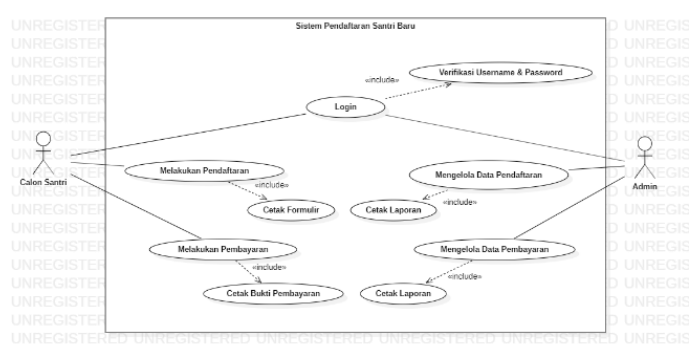

Gambar 1. Use Case Diagram Pendaftaran Santri Baru

Tabel 1. Deskripsi Use Case Diagram Login

\begin{tabular}{|l|l|}
\hline $\begin{array}{l}\text { Use Case } \\
\text { Name }\end{array}$ & Login \\
\hline Requirements & A1 \\
\hline Goal & $\begin{array}{l}\text { Calon santri dapat } \\
\text { menampilkan menu } \\
\text { pendaftaran }\end{array}$ \\
\hline $\begin{array}{l}\text { Pre- } \\
\text { Condutions }\end{array}$ & $\begin{array}{l}\text { Calon santri telah } \\
\text { melakukan registrasi }\end{array}$ \\
\hline
\end{tabular}

\begin{tabular}{|l|l|}
\hline $\begin{array}{l}\text { Post- } \\
\text { Condutions }\end{array}$ & $\begin{array}{l}\text { Sistem menampilkan } \\
\text { halaman beranda }\end{array}$ \\
\hline $\begin{array}{l}\text { Failed end } \\
\text { Condutions }\end{array}$ & $\begin{array}{l}\text { Calon santri tidak dapat } \\
\text { melakukan login }\end{array}$ \\
\hline Actors & Calon santri \\
\hline Main Flow/ & $\begin{array}{l}\text { 1. calon santri } \\
\text { membuka } \\
\text { Basic Path } \\
\text { halamanlogin. }\end{array}$ \\
& $\begin{array}{l}\text { 2. calon santri mengisi } \\
\text { email dan No hp. } \\
\text { calon santri bisa } \\
\text { masuk kehalaman } \\
\text { utama system }\end{array}$ \\
\hline sAlternate & - \\
Flow/ Invariant & \\
A Invariant B & - \\
\hline
\end{tabular}


Tabel 2. Deskripsi Use Case Diagram Melakukan Pendaftaran

\begin{tabular}{|l|l|}
\hline $\begin{array}{l}\text { Use Case } \\
\text { Name }\end{array}$ & Melakukan Pendaftaran \\
\hline Requirements & A2 \\
\hline Goal & $\begin{array}{c}\text { Calon santri sudah } \\
\text { dapat } \\
\text { melakukan }\end{array}$ \\
\hline $\begin{array}{l}\text { Pre- } \\
\text { Condutions }\end{array}$ & $\begin{array}{l}\text { Calon santri membuka } \\
\text { web pendaftaran }\end{array}$ \\
\hline $\begin{array}{l}\text { Post- } \\
\text { Condutions }\end{array}$ & $\begin{array}{l}\text { Calon santri telah } \\
\text { melakukan pendaftaran }\end{array}$ \\
\hline $\begin{array}{l}\text { Failed end } \\
\text { Condutions }\end{array}$ & $\begin{array}{l}\text { Calon santri tidak dapat } \\
\text { melakukan pendaftaran }\end{array}$ \\
\hline Actors & Calon santri \\
\hline $\begin{array}{l}\text { Main Flow/ } \\
\text { Basic Path }\end{array}$ & $\begin{array}{l}\text { 1. Calon santri } \\
\text { langsung masuk } \\
\text { kehalaman website } \\
\text { sekolah } \\
\text { 2. Calon santri langsung } \\
\text { mengisi form } \\
\text { pendaftaran } \\
\text { Alow/ Invariant }\end{array}$ \\
\hline Invariant B & $\begin{array}{l}\text { Simpan santri mengklik } \\
\text { 4. Sistem menampilkan } \\
\text { bukti pendaftaran }\end{array}$ \\
\hline -
\end{tabular}

Tabel 3. Deskripsi Use Case Diagram Melakukan Pembayaran

\begin{tabular}{|l|l|}
\hline $\begin{array}{l}\text { Use Case } \\
\text { Name }\end{array}$ & Melakukan Pembayaran \\
\hline Requirements & A4 \\
\hline Goal & $\begin{array}{l}\text { Calon santri melakukan } \\
\text { pembayaran }\end{array}$ \\
\hline $\begin{array}{l}\text { Pre- } \\
\text { Condutions }\end{array}$ & $\begin{array}{l}\text { Calon santri melakukan } \\
\text { login }\end{array}$ \\
\hline
\end{tabular}

\begin{tabular}{|c|c|}
\hline $\begin{array}{l}\text { Post- } \\
\text { Condutions }\end{array}$ & $\begin{array}{l}\text { Calon santri sudah } \\
\text { melakukan Pembayaran }\end{array}$ \\
\hline $\begin{array}{l}\text { Failed end } \\
\text { Condutions }\end{array}$ & $\begin{array}{l}\text { Calon santri tidak bisa } \\
\text { melakukan Pembayaran }\end{array}$ \\
\hline Actors & Calon santri \\
\hline $\begin{array}{l}\text { Main Flow/ } \\
\text { Basic Path }\end{array}$ & $\begin{array}{l}\text { 1. Calon santri mengklik } \\
\text { pembayaran } \\
\text { 2. Sistem menampilkan } \\
\text { form pembayaran } \\
\text { 3. User mengisi No } \\
\text { Pembayaran, No } \\
\text { Pendaftaran, Nama } \\
\text { Lengkap, Tanggal } \\
\text { Pembayaran, No } \\
\text { Rekening, Jumlah } \\
\text { Pembayaran } \\
\text { 4. Klik Bayar }\end{array}$ \\
\hline $\begin{array}{l}\text { sAlternate } \\
\text { Flow/ Invariant } \\
\text { A }\end{array}$ & - \\
\hline Invariant B & - \\
\hline
\end{tabular}

Tabel 4. Deskripsi Use Case Diagram Login Admin

\begin{tabular}{|l|l|}
\hline $\begin{array}{l}\text { Use Case } \\
\text { Name }\end{array}$ & Login Admin \\
\hline Requirements & B1 \\
\hline Goal & $\begin{array}{l}\text { Admin dapat masuk } \\
\text { kesistem }\end{array}$ \\
\hline Pre-Condutions & $\begin{array}{l}\text { Admin belum melakukan } \\
\text { login }\end{array}$ \\
\hline $\begin{array}{l}\text { Post- } \\
\text { Condutions }\end{array}$ & $\begin{array}{l}\text { Sistem menampilkan } \\
\text { halaman beranda }\end{array}$ \\
\hline $\begin{array}{l}\text { Failed end } \\
\text { Condutions }\end{array}$ & $\begin{array}{l}\text { Admin tidak dapat } \\
\text { melakukan login }\end{array}$ \\
\hline Actors & Admin \\
\hline $\begin{array}{l}\text { Main Flow/ } \\
\text { Basic Path }\end{array}$ & $\begin{array}{l}\text { 1. Admin masuk } \\
\text { kehalaman login } \\
\text { 2. Admin mengisi } \\
\text { username dan } \\
\text { password } \\
\text { 3. Admin bisa masuk ke } \\
\text { halaman beranda } \\
\text { admin }\end{array}$ \\
\hline $\begin{array}{l}\text { Invariant A } \\
\text { Invariant B }\end{array}$ & $\begin{array}{l}\text { - } \\
\text { Itternate Flow/ }\end{array}$ \\
\hline
\end{tabular}


Tabel 5. Deskripsi Use Case Diagram Mengelola Data Pendaftaran

\begin{tabular}{|l|l|}
\hline $\begin{array}{l}\text { Use Case } \\
\text { Name }\end{array}$ & $\begin{array}{l}\text { Mengelola data } \\
\text { pendaftaran }\end{array}$ \\
\hline Requirements & B2 \\
\hline Goal & $\begin{array}{l}\text { Admin dapat mengelola } \\
\text { data pendaftaran }\end{array}$ \\
\hline Pre-Condutions & $\begin{array}{l}\text { Admin sudah melakukan } \\
\text { login }\end{array}$ \\
\hline $\begin{array}{l}\text { Post- } \\
\text { Condutions }\end{array}$ & $\begin{array}{l}\text { Data pendaftaran } \\
\text { berhasil di ubah }\end{array}$ \\
\hline
\end{tabular}

\begin{tabular}{|c|c|}
\hline $\begin{array}{l}\text { Failed end } \\
\text { Condutions }\end{array}$ & $\begin{array}{l}\text { Admin tidak dapat } \\
\text { mengelola data } \\
\text { pendaftaran }\end{array}$ \\
\hline Actors & Admin \\
\hline $\begin{array}{l}\text { Main Flow/ } \\
\text { Basic Path }\end{array}$ & $\begin{array}{l}\text { 1. Admin melakukan } \\
\text { login } \\
\text { 2. Tampil beranda } \\
\text { admin } \\
\text { 3. Pilih menu } \\
\text { pendaftaran } \\
\text { 4. Tampil list data } \\
\text { pendaftaran }\end{array}$ \\
\hline $\begin{array}{l}\text { sAlternate } \\
\text { Flow/ Invariant } \\
\text { A }\end{array}$ & - \\
\hline Invariant B & - \\
\hline
\end{tabular}

Tabel 6. Deskripsi Use Case Diagram Mengelola Data Pembayaran

\begin{tabular}{|l|l|}
\hline Use Case Name & $\begin{array}{l}\text { Mengelola data } \\
\text { pembayaran }\end{array}$ \\
\hline Requirements & B3 \\
\hline Goal & $\begin{array}{l}\text { Admin dapat mengelola } \\
\text { data pembayaran }\end{array}$ \\
\hline Pre-Condutions & $\begin{array}{l}\text { Admin sudah melakukan } \\
\text { login }\end{array}$ \\
\hline Post-Condutions & $\begin{array}{l}\text { Data pembayaran } \\
\text { berhasil di ubah }\end{array}$ \\
\hline $\begin{array}{l}\text { Failed end } \\
\text { Condutions }\end{array}$ & $\begin{array}{l}\text { Admin tidak dapat } \\
\text { mengelola data } \\
\text { pembayaran }\end{array}$ \\
\hline Actors & Admin \\
\hline Main Flow/ & $\begin{array}{l}\text { 1. Admin melakukan login } \\
\text { Basic Path }\end{array}$ \\
$\begin{array}{l}\text { 2. Tampil beranda admin } \\
\text { 3. Pilih menu } \\
\text { pembayaran }\end{array}$ \\
\hline
\end{tabular}

\begin{tabular}{|l|l|}
\hline & $\begin{array}{l}\text { 4. Tampil list data } \\
\text { pembayaran }\end{array}$ \\
\hline $\begin{array}{l}\text { sAlternate Flow/ } / ~-~ \\
\text { Invariant A }\end{array}$ \\
\hline Invariant B & - \\
\hline
\end{tabular}

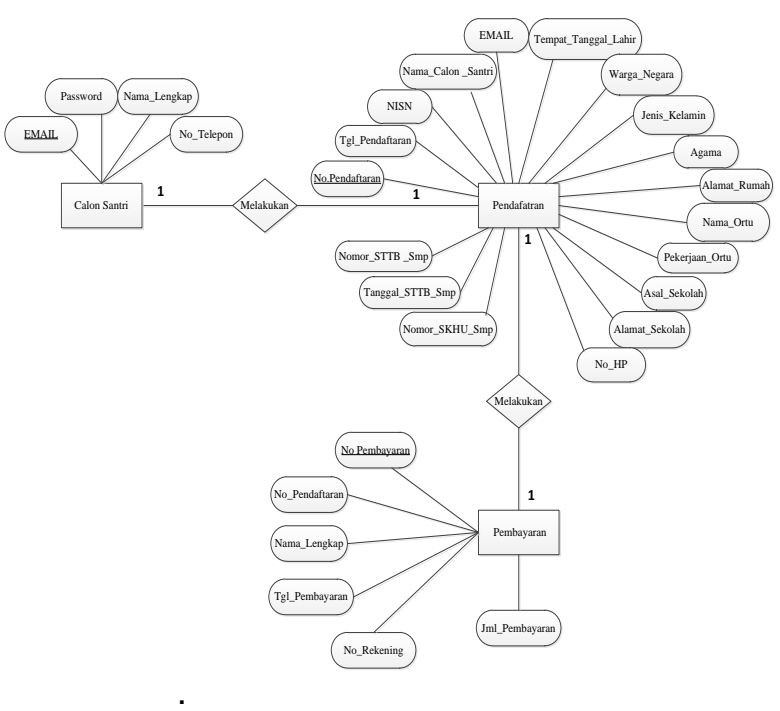

Gambar 2. Rancangan ERD Pendaftaran Santri Baru

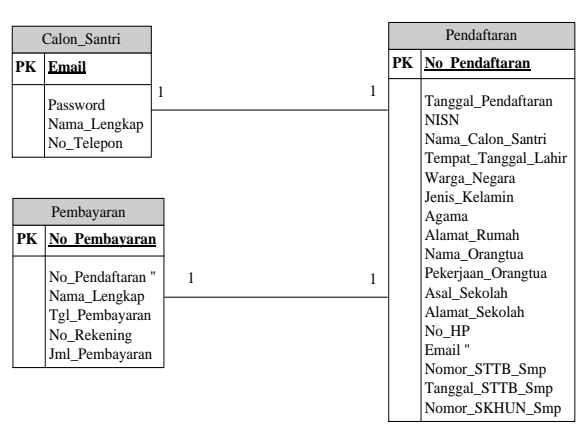

Gambar 3. Rancangan LRS Pendaftaran Santri Baru 


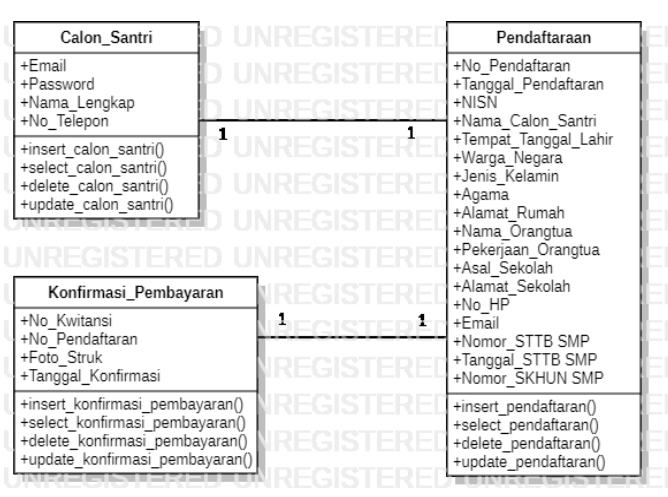

Gambar 4. Class Diagram Pendaftaran Santri Baru

\section{Spesifikasi Hardware \& Software}

1. Spesifikasi Hardware

A. Server

(a) CPU, Processor Intel® Pentium ${ }^{\circledR}$ Core 2 Duo

(b) RAM DDR2 4 GB

(c) Hard Disk $500 \mathrm{~GB}$

B.Client

1) CPU, (a)Processor Intel $\AA$ Pentium $\AA 4$, RAM DDR2 1GB, Hard Disk 20 GB

2) Mouse

3) Keyboard

4) Monitor dengan resolusi layar minimum $1024 \times 768$

5) Koneksi internet dengan kecepatan 56 kbps.

2.. Spesifikasi Software

1. Server

A. Sistem operasi yang digunakan Microsoft Windows.

B.Aplikasi penyimpan database yg digunakan Microsoft Access 2013

C. Bahasa pemrograman yang digunakan menggunakan dreamweaver

3. Client

A. Sistem operasi yang digunakan Microsoft Windows.

B. Aplikasi penyimpan database yg digunakan Microsoft Access 2013

C.Bahasa pemrograman yang digunakan menggunakan dreamweaver

\section{Kesimpulan}

Berdasarkan hasil permbahasan yang telah diuraikan pada bab-bab sebelumnya, maka penulis dapat menarik kesimpulan sebagai berikut :
1. Dengan sistem penerimaan santri baru yang dilakukan secara online maka calon santri tidak harus menunggu cetakan surat edaran dan formulir dari pesantren.

2. Dengan sistem penerimaan santri baru ini calon santri tidak harus memastikan pengumuman dan jadwal dengan datang langsung ke sekolah melainkan dengan mengakses aplikasi web sistem penerimaan santri baru online.

3. Dengan sistem penerimaan santri baru ini calon santri tidak harus datang ke sekolah untuk melakukan pendaftaran dan pembayaran melainkan dengan mengakses aplikasi web sistem penerimaan santri baru online dengan mengisi form dan lampiran yang tersedia dalam aplikasi.

4. Dan dengan sistem informasi penerimaan santri baru ini dapat membantu dan bermanfaat bagi pihak sekolah, calon santri serta seluruh mitra kerja yang bersangkutan dalam sistem.

\section{Referensi}

A. S., R., \& Shalahuddin, M. (2015). Rekayasa Perangkat Lunak Terstruktur dan Berorientasi Objek. Bandung: Informatika Bandung.

Anwar, S., \& Irawan, F. (2017). Pengadaan Suku Cadang Mobil. Jurnal Pilar Nusa Mandiri, 13(1), 113-121.

Djahir, M. Y., \& Pratita, S. D. (2015). Bahan Ajar Sistem Informasi Manajemen. Yogyakarta: Deepublish.

Fridayanthie, E. W., \& Mahdianti, T. (2016). Rancang Bangun Sistem Informasi Permintaan ATK Berbasis Intranet. Jurnal IImu Komputer, 4(2).

Hidayatullah, P., \& Kawistara, J. K. (2017). Pemrograman WEB Edisi Revisi. Bandung: Penerbit Informatika.

Hutahaean, J. (2015). Konsep Sistem Informasi. Yogyakarta: Deepublish.

Kesuma, C., \& Rahmawati, L. (2017). Sistem Informasi Akademik Berbasis Web Pada SMK Purnama 2 Banyumas. Jurnal 
Indonesia tentang Jejaring dan Keamanan, 7(3), 1-9.

Madcoms. (2016). Sukses Membangun Toko Online dengan PHP \& MySQL. Yogyakarta: CV Offset Andi.

Maulana, S. (2015). Lima Proyek SMS Gateway. Jakarta: Elex Media Komputindo.

Mulyani, A. S. (2016). Metode Analisis dan Perancangan Sistem. Bandung: Abdi Sistematika.

Pratama, A. E. (2014). Sistem Informasi dan Implementasinya. Bandung: Informatika Bandung.

Puspitasari, D. (2016). Sistem Informasi Perpustakaan Sekolah Berbasis Web.
Jurnal Pilar Nusa Mandiri, 12(2).

R, H., \& A, F. (2018). Pengungkapan Pihak-Pihak Berelasi Pada Perusahaan-Perusahaan Salim Group Yang Terdaftar di Bursa Efek Indonesia. Junal Online Insan Akuntan, 3(2), 185-196.

Sihombing, D. (2016). Perancangan Sistem Informasi Pelaporan Masyarakat Untuk Kerusakan Jalan Di Pontianak Menggunakan Google Maps Api. Jurnal Khatulistiwa Informatika, 4(1).

Sutabri, T. (2016). Sistem Informasi Manajemen. Yogyakarta: CV Andi Offset. 